\title{
LA UNIVERSIDAD Y EL LUCRO: CÓMO IMPEDIRLO Y POR QUÉ*
}

\author{
Carlos Peña \\ Universidad Diego Portales
}

La palabra lucro se emplea en dos sentidos: (i) para aludir a los excedentes de una cierta actividad y (ii) para designar al destino de esos excedentes. Así una universidad puede realizar actividades lucrativas (en el primer sentido), pero reinvertir en sus propios fines (en cuyo caso no tiene lucro en el segundo sentido). Respecto del destino de los excedentes de las universidades (lucro en el segundo sentido) deben responderse dos preguntas:

¿Deben permitirse universidades con fines de lucro, es decir, que sus controladores puedan apropiarse de los excedentes? La evidencia disponible indica que es mejor prohibirlas, pues esas instituciones carecen hoy de legitimidad, ayudan a concentrar el poder económico y cultural, pueden perjudicar en el mediano plazo la calidad y no son la única manera de masificar el sistema de educación superior.

¿Cómo asegurar que la regla que prohíbe el lucro no se eluda? Ello puede alcanzarse si: a) se prohíben los contratos con sociedades relacionadas; b) se prohíbe que las sociedades comerciales sean miembros de las corporaciones universitarias; c) se declara nula la cesión a cualquier título del control de la universidad; d) se establecen directorios independientes y personalmente responsables por las decisiones que adoptan; e) se confiere a la Superintendencia el deber de perseguir la responsabilidad de los directores de oficio o a petición de parte. Las reglas anteriores corregirían el principal problema del sistema universitario hoy: su extrema desregulación que lo hace vivir en estado de naturaleza, deslegitimando el importante tránsito que ha experimentado, desde un sistema de élites y excluyente, a uno inclusivo y de masas.

Carlos Peña. Rector de la Universidad Diego Portales, profesor asociado, Facultad de Derecho, Universidad de Chile. Dirección: carlospena@udp.cl.

* Exposición en el seminario "Lucro y Universidad" realizado el 28 de agosto de 2012 en el CEP. Véanse asimismo en esta edición las ponencias presentadas en esa oportunidad por Carlos Williamson, Arturo Fontaine y Ricardo Paredes. (N. del E.) 
$\mathrm{P}$

ocas palabras han sido empleadas, el último tiempo, con mayor profusión y entusiasmo que la palabra lucro. Ella aparece en carteles callejeros, en libros e investigaciones, en consignas encendidas, en eslóganes y en declaraciones de diversa índole. Sin embargo, y a pesar del entusiasmo y la reiteración con que se la emplea, no siempre resulta claro con qué significado se la utiliza.

Así entonces, a la hora de analizar las relaciones que median entre la institución universitaria y el lucro, resulta imprescindible comenzar preguntándonos qué hemos de entender por él.

El lucro, como todo el mundo debería saber, posee dos significados claramente diferenciados entre sí.

Por una parte, se emplea la palabra lucro para aludir a la diferencia que media entre lo que se da y lo que se recibe.

En la Suma Teológica, por ejemplo, Santo Tomás distingue entre el intercambio natural o necesario (que se verificaría cuando alguien da algo que no necesita a cambio de algo que necesita) y el lucrativo (donde alguien da dinero u otro bien por el afán de obtener más dinero). El Doctor Angélico, como suele llamársele, decía que el intercambio de este segundo tipo debía desalentarse porque, dice, "el afán de lucro es infinito" y no tiende por su naturaleza a un fin bueno (Suma Teológica, II-IIae q.77, a 4) ${ }^{1}$. Siglos después, Marx efectúa, en El Capital, la

1 Es propio - observa Santo Tomás - de los comerciantes dedicarse a los cambios de las cosas; y como observa el filósofo en I Pol., tales cambios son de dos especies: una, como natural y necesaria, es decir, por la cual se hace el trueque de cosa por cosa o de cosas por dinero para satisfacer las necesidades de la vida; tal clase de cambio no pertenece propiamente a los comerciantes, sino más bien a los cabezas de familia o a los jefes de la ciudad, que tienen que proveer a su casa o a la ciudad de las cosas necesarias para la vida; la segunda especie de cambio es la de dinero por dinero o cualquier objeto por dinero, no para proveer las necesidades de la vida, sino para obtener algún lucro; y este género de negociación parece pertenecer, propiamente hablando, al que corresponde a los comerciantes. Mas, según el filósofo, la primera especie de cambio es laudable, porque responde a la necesidad natural; mas la segunda es con justicia vituperada, ya que por su misma naturaleza fomenta el afán de lucro, que no conoce límites, sino que tiende al infinito. De ahí que el comercio, considerado en sí mismo, encierre cierta torpeza, porque no tiende por su naturaleza a un fin honesto y necesario.

No obstante, el lucro, que es el fin del comercio, aunque en su esencia no entrañe algún elemento honesto o necesario, tampoco implica por esencia nada vicioso o contrario a la virtud. Por consiguiente, nada impide que ese lucro sea ordenado a un fin necesario o incluso honesto, y entonces la negocia- 
misma distinción sólo que él la efectúa entre lo que llama "circulación simple" (cuando alguien intercambia una mercancía por dinero a fin de obtener otra mercancía, que es lo que hace el trabajador) y "circulación capitalista" (en este último caso se da dinero por una mercancía a fin de obtener más dinero) (El Capital, sección segunda, capítulo iv). A pesar que coincide con el Doctor Angélico a la hora de hacer la distinción, Marx piensa que esta última forma de intercambio es inherente a la acumulación y al progreso que el capitalismo hace posible.

Ahora bien, cuando se sostiene que las universidades no deben perseguir el lucro, y se emplea esta última palabra en el sentido que acabo de identificar, lo que se quiere decir es que la universidad, y el conjunto de sus miembros, deben estar sustraídos de la circulación del capital y de las leyes de la mercancía. Mientras la mayor parte de los seres humanos configura su vida mediante el intercambio, las universidades, se sugiere a veces, deberían estar al margen.

Pero por otra parte, la palabra lucro tiene un sentido estrictamente jurídico.

Cuando se la usa en un sentido jurídico, se la emplea para designar no la diferencia entre lo que se da y lo que se recibe, sino para aludir al destino de los excedentes que son producto de una determinada actividad. En este caso, decir que una cierta institución es sin fines de lucro no significa que ella no participe, por decirlo así, de las leyes de la circulación y de la acumulación capitalista. Lo que se quiere decir es que las ganancias o excedentes que obtenga deben ser reinvertidos o destinados al fin específico para el que la institución que los obtiene fue creada (así lo estableció un Informe del Consejo de Defensa Fiscal: "No procede otorgar personalidad jurídica a las asociaciones que persiguen beneficios económicos indirectos de carácter colectivo") $)^{2}$.

Así entonces, hay dos sentidos en los que puede reclamarse que una universidad no tenga fines de lucro. En uno de ellos se trata de sustraer a la universidad de los avatares del mercado global y a sus miembros, especialmente a los profesores, de los sudores de la competencia. En el otro sentido, en cambio, no se trata de sustraer a la universidad

ción se volverá lícita. Así ocurre cuando un hombre destina el moderado lucro que adquiere mediante el comercio al sustento de la familia o también a socorrer a los necesitados, o cuando alguien se dedica al comercio para servir al interés público, para que no falten a la vida de la patria las cosas necesarias, pues entonces no busca el lucro como un fin, sino remuneración de su trabajo.

${ }^{2} R D J$, Tomo XXXIX, 1942, primera parte, pp. 117-123. 
de los avatares de la competencia y de la acumulación, sino nada más lograr que los excedentes que la universidad obtenga no sean apropiados por individuos u organizaciones ajenos a ella y con fines distintos a la tarea que la legitima.

Si bien en el debate en Chile ambos conceptos suelen confundirse - puesto que a veces parece exigirse que la universidad se sustraiga de la competencia y del mercado y en otras que cumpla la ley actualmente existente - en lo que sigue distinguiré ambos problemas y me referiré a ellos en el mismo orden en que los acabo de enunciar.

Consideremos brevemente el primero de ellos.

El primer problema atinge a las relaciones entre la universidad y la circulación del capital ¿deben las universidades estar sometidas a los rigores de la acumulación del capital y de la competencia para funcionar o, en cambio, deben estar al margen de esas leyes y entregadas, por ejemplo, a alguna forma de mecenazgo estatal o de otra índole? Humboldt, en el discurso de instalación de la Universidad de Berlín, pareció creer que la universidad debía ponerse al margen de la circulación de mercancías: permitan que la universidad se dedique solo a la ciencia, dijo en el discurso inaugural, y todo lo demás vendrá por añadidura ${ }^{3}$. Hoy día las universidades en casi todo el mundo - y en Chile, para qué decir- deben buscar sus propios recursos, o los profesores los suyos, mediante diversas formas de emprendimiento o de competencia. Las universidades, en otras palabras, están cada vez más integradas a lo que Marx llamaba la circulación del capital ¿es necesaria alguna reforma o intervención en este ámbito, en este primer problema que menciono?

${ }^{3}$ El Estado no debe considerar a sus universidades ni como centros de segunda enseñanza ni como escuelas especiales, ni servirse de sus academias como diputaciones técnicas o científicas. En general (pues más adelante diremos qué excepciones concretas deben admitirse respecto a las universidades), no debe exigirles nada que se refiera directamente a él, sino abrigar el íntimo convencimiento de que en la medida en que cumplan con el fin último que a ellas corresponde cumplen también con los fines propios de él, y además, desde un punto de vista mucho más alto, desde un punto de vista que permite una concentración mucho mayor y la movilización de fuerzas y resortes que el Estado no puede poner en movimiento (vid. Fichte et al., La Idea de la Universidad en Alemania, p. 214). 
Pienso que sí, que aunque es necesario tolerar el llamado capitalismo académico - por los beneficios que provee por ejemplo en las relaciones con la empresa - hay también que ponerle límites (límites, no obstáculos) como una forma de resguardar la misión crítica que el trabajo universitario debe poseer en la sociedad. Una universidad puramente funcional, una universidad de emprendedores y no de intelectuales, una universidad que carece de roces con la sociedad en medio de la que funciona, no está, me parece a mí, a la altura de su tarea. Si las universidades nada más cumplieran la función de incrementar el capital humano, entonces no tendría nada de malo que ellas se ajustaran funcionalmente a la circulación capitalista (es decir, que sus actividades estuvieran movidas nada más que por las necesidades de acumulación); pero ocurre que las universidades tienen otras múltiples funciones que van desde incrementar la cohesión social a despertar el espíritu reflexivo de sus miembros y estas últimas funciones pueden ser desalentadas si, para desarrollarlas, se confía sólo en el anhelo de excedentes de sus miembros.

Hay entonces que evitar que la universidad se entregue por entero a lo que Marx llamaba la circulación capitalista.

La universidad moderna nació atada a ideales emancipatorios y a una idea de saber que, no hay duda, parece estar en crisis. Es verdad: ya no es posible pensar a la institución universitaria como el lugar en el que se discierne, y se transmite, lo que es necesario para la libertad o donde se consuma la vida del espíritu. La pérdida de centralidad del estado nacional (que deja, en buena medida, a la universidad sin el sujeto al que originariamente servía); el decaimiento de los metarrelatos (que desprovee de un único sentido al conjunto de sus actividades); y la expansión del mercado (que estimula las conductas orientadas a la búsqueda de rentas), lo impiden. También es verdad que algunos de los valores típicamente universitarios (desinterés institucional, comunismo de resultados, búsqueda de la verdad sin otra consideración) son más débiles que antes o poseen hoy menos fuerza inspiradora. Pero todas esas son buenas razones para tratar de salvar esa dimensión del trabajo universitario y no razones, como a veces se cree, para abandonarla. La dimensión reflexiva del trabajo universitario - esa función que Kant asignaba a lo que él llamaba la facultad inferior- sigue siendo lo más peculiar de la universidad y sin ella las tareas de investigación y de docencia seguirían siendo dignas y útiles; pero no poseerían la particular dignidad que hasta ahora le conferimos. Si bien esa tarea - una tarea crítica en el sentido kantiano - ya no puede ser llevada a cabo en la 
confianza absoluta del saber concebido como totalidad, ese concepto límite - la búsqueda de un saber que se sabe imposible (Derrida, Universidad sin condición, 2002) - sigue estando en el centro del relato que legitima a la vida universitaria.

¿Hay entonces que sustraer del todo a las universidades de las leyes del capital?

No parece posible. Y tampoco conveniente que todas las universidades se aparten de lo que Marx llamaba la circulación del capital, se pongan al margen del lucro en este primer sentido.

Los sistemas de educación superior de masas serían inimaginables si demandáramos de todas las instituciones de educación superior una tarea puramente crítica sustraída a las reglas del capital y del mercado. Instituciones, por decirlo así, puramente humboldtianas no serían capaces de llevar adelante la masificación que las sociedades modernas y democráticas inevitablemente demandan. Lo que se requiere entonces es que el Estado asegure la existencia de un puñado de instituciones que cumplan esas tareas y orienten normativamente el conjunto del sistema.

Como lo muestra el caso de Chile - no vale la pena negar los hechos- la modernización capitalista puede ser extremadamente dinámica a la hora de expandir el acceso a bienes que hasta hace poco estaban nada más que a disposición de una minoría. Nuestro país ha transitado en apenas dos o tres décadas, desde un sistema de educación superior de élites a uno de masas gracias al proceso modernizador que se produjo en la dimensión material de la existencia. A pesar de los problemas que presenta (y que la literatura revela como habituales en estos procesos: bajo capital cultural de los recién incorporados, frustración inicial de sus altas expectativas, menos énfasis en las humanidades y preferencia por las profesiones, pérdida del aura aristocratizante de la universidad), ese proceso ha profundizado la democracia, la secularización de la cultura y la autonomía individual.

El problema no es, pues, ni la masificación de la educación superior, ni la proliferación de instituciones, ni la presencia del capitalismo académico, sino la falta de regulación del proceso. El tránsito entre un sistema de élites a uno de masas se ha producido en medio de un estado de naturaleza carente de reglas. Esa dinámica — donde el proceso modernizador queda entregado a sí mismo- es el que es imprescindible corregir. No para ahogarlo — puesto que, como ya se dijo, él provee importantes bienes que están a la base de la cultura democrática - sino para conducirlo. 
Ahora bien ¿cómo se corrige ese proceso?

Una primera decisión para conducir y gobernar ese proceso es, como se sugiere, la de mantener, al menos para algunas instituciones encargadas de orientar normativamente el sistema, alguna forma de mecenazgo estatal. Ponerlas, en otras palabras, en una medida importante, al margen del lucro en el primer sentido que ya se analizó. Ese mecenazgo les permitiría liberarse, siquiera parcialmente, de los rigores de la competencia y la búsqueda de rentas emprendiendo actividades reflexivas y críticas que carecen de excedentes.

Una segunda decisión - a la que ahora me referiré- debe ser la de contar con reglas claras relativas a los excedentes de las universidades (es decir, con el lucro en el segundo sentido que denantes distinguí). Ello exige, como se verá de inmediato, decidir si han de admitirse las universidades con fines de lucro o no y pensar cómo se asegura que las universidades sin fines de lucro lo sean efectivamente.

Hoy día en el derecho vigente en Chile las reglas proscriben a las universidades con fines de lucro. Esta regla plantea, como se acaba de decir, dos problemas que es necesario examinar separadamente: uno, si acaso esa regla debe mantenerse o si, en cambio, debe permitirse la existencia de universidades con fines de lucro; dos, si el sistema legal cuenta con mecanismos para asegurar que las universidades que formalmente carecen de fines de lucro sean, efectivamente, fieles a esa índole que declaran.

Examinemos brevemente en esta sección el primer problema que este segundo significado del lucro plantea.

¿Debe mantenerse la regla que proscribe a las universidades con fines de lucro o, en cambio, esa regla debe sustituirse por una que permita la existencia de ese tipo de universidades?

Las razones a favor de la admisión de ese tipo de universidades fueron examinadas en el Informe del Consejo Asesor de la Educación Superior ${ }^{4}$. La mayoría de ese Consejo dijo allí que lo decisivo era la política estatal hacia ese tipo de instituciones: si la política estatal, se sugería en ese informe, era restrictiva desde el punto de vista del

${ }^{4}$ Puede consultarse en www.ubiobio.cl/web/descargas/InformeCAPfinal.pdf. 
financiamiento y transparente en la información, podía permitirse su existencia. Una política estatal restrictiva hacia ese tipo de instituciones (tanto en el financiamiento a la oferta como a la demanda) cumplía los mismos objetivos de una regla de prohibición y era menos restrictiva de la libertad según el principio de ponderación ${ }^{5}$. La misma idea se reiteró en el seminario que dio origen a este artículo ${ }^{6}$.

Sin embargo, el debate público ha puesto de manifiesto que esa ponderación es errónea.

El debate público en Chile muestra, en efecto, que es mejor una regla de prohibición, a pesar de lo que la mayor parte de ese Consejo sugirió entonces ${ }^{7}$. Las razones son las que siguen.

a) Desde luego, ese tipo de instituciones podría carecer hoy, en la cultura pública de Chile, de toda legitimidad. La legitimidad — las razones socialmente eficaces para confiar-son esenciales en la tarea educativa. Si esa condición no se cumple - como ocurre hoy con ese tipo de instituciones - el proceso educativo se viene abajo.

b) El debate público ha mostrado también que el argumento que acentúa la calidad de la provisión educativa por sobre la índole del proveedor puede ser una falacia: la calidad de la formación en educación superior no es independiente del ethos de las instituciones. Una institución con fines de lucro orientada en exclusiva a la docencia estandarizada y a la mera funcionalidad (como la experiencia muestra tienden a ser en el largo plazo este tipo de instituciones) carece de algunos aspectos, como la promoción de una cultura reflexiva, que son esperables de la experiencia universitaria. Por supuesto, hay entidades sin fines de lucro que, por otras razones, por ejemplo la adhesión religiosa o ideológica, también perjudican la índole reflexiva de la tarea universitaria.

${ }^{5}$ El principio de ponderación formulado por Alexy, indica que entre dos reglas que persiguen un mismo bien, hay que preferir aquella que permita alcanzarlo al menor coste en otros bienes competitivos.

${ }^{6}$ Fue el punto de vista que expuso Arturo Fontaine quien, a pesar del pobre desempeño que atribuye a ese tipo de universidades (y la opinión desfavorable que por eso le merecen), piensa que no deben prohibirse porque ello restringiría en demasía la libertad.

${ }^{7} \mathrm{El}$ autor de este texto formó parte de esa mayoría que sugirió podía admitirse la existencia de universidades con fines de lucro a condición que hubiera transparencia absoluta y una política estatal restrictiva en el financiamiento. Opinaban de la misma forma el rector de la Universidad Católica, de la Universidad de Santiago, de la Universidad de la Frontera, entre otros. 
c) Ese mismo debate ha puesto de manifiesto que la asociación que suele hacerse entre masificación y tolerancia hacia el lucro no es correcta. La experiencia comparada muestra que la masificación puede alcanzarse sin tolerar la existencia de ese tipo de instituciones. A veces se insinúa a favor de las universidades con fines de lucro, que ellas hacen posible la masificación; otras veces se citan los defectos de la masificación (por ejemplo, el bajo capital cultural de los estudiantes) como un resultado de las instituciones con fines de lucro. Se trata en ambos casos de un error: la masificación es valiosa y es independiente de la índole de las instituciones.

d) En fin, dada la concentración del poder en Chile, permitir que las instituciones de transmisión cultural y formación de las élites estén explícitamente en manos de grupos empresariales, en la más absoluta promiscuidad, les haría daño a los objetivos de difusión del poder que son propios de la democracia.

Así entonces debe concluirse que si, como todos dicen creer, hay que desalentar la existencia de ese tipo de instituciones, es mejor una regla de prohibición que una mera política estatal restrictiva desde el punto de vista del financiamiento.

Ahora bien ¿cómo asegurar que las universidades sean fieles a esa regla?

¿Hay en el derecho vigente en Chile reglas para asegurar que las universidades reinviertan la totalidad de los excedentes que obtienen, es decir, reglas que permitan asegurar la índole sin fines de lucro que declaran?

La respuesta a esa pregunta es que no: no hay reglas que permitan asegurar el carácter sin fines de lucro que las universidades, desde el punto de vista legal, debieran poseer. Las universidades están hoy en medio de un verdadero estado de naturaleza, entregadas a la audacia o la prudencia de quienes las manejan. Por lo mismo es imprescindible imaginar reglas que permitan a todos cerciorarse que las universidades son fieles a la índole que, desde el punto de vista legal, declaran.

¿Cuáles son las formas habituales — cabría preguntarse - en las que esa regla se infringe y cuáles son las reglas que debieran dictarse para evitar que ello ocurra de nuevo? En lo que sigue, enumeraré las di- 
versas formas en que se elude la ley y, al mismo tiempo, señalaré cómo, en mi opinión, ello podría evitarse ${ }^{8}$.

i) Ante todo, esa regla se infringe cuando la universidad realiza contratos y efectúa transferencias con sociedades relacionadas a precios que están por sobre o por debajo de los del mercado.

¿Qué debe entenderse por sociedades relacionadas?

La expresión "sociedades relacionadas" tiene un sentido técnico que la ley define ${ }^{9}$. En conformidad a él, dos sociedades son relaciona-

${ }^{8}$ Sobra decir que la regla que vamos a analizar debe respetarse $-\mathrm{y}$ el sistema legal debe procurar que se respete- con prescindencia de si las universidades con fines de lucro se aceptan o no. El problema de si se admiten o no las universidades con fines de lucro, dice relación con la amplitud de la regla (a qué instituciones se aplica) y no con su obligatoriedad.

${ }^{9}$ Las reglas que definen las operaciones relacionadas, son las que siguen: al cual:

Se encuentra en primer lugar el artículo 146 de la ley 18.046, conforme

[S]on operaciones con partes relacionadas de una sociedad anónima abierta toda negociación, acto, contrato u operación en que deba intervenir la sociedad y, además, alguna de las siguientes personas:

1) Una o más personas relacionadas a la sociedad, conforme al artículo 100 de la ley $\mathrm{N}^{\circ} 18.045$.

2) Un director, gerente, administrador, ejecutivo principal o liquidador de la sociedad, por sí o en representación de personas distintas de la sociedad, o sus respectivos cónyuges o parientes hasta el segundo grado de consanguinidad o afinidad inclusive.

3) Las sociedades o empresas en las que las personas indicadas en el número anterior sean dueños, directamente o a través de otras personas naturales o jurídicas, de un $10 \%$ o más de su capital, o directores, gerentes, administradores, ejecutivos principales.

4) Aquellas que establezcan los estatutos de la sociedad o fundadamente identifique el comité de directores, en su caso, aun cuando se trate de aquellas indicadas en el inciso final del artículo 147.

5) Aquellas en las cuales haya realizado funciones de director, gerente, administrador, ejecutivo principal o liquidador, un director, gerente, administrador, ejecutivo principal o liquidador de la sociedad, dentro de los últimos dieciocho meses.

En segundo lugar se encuentra el artículo 100 de la ley $\mathrm{N}^{\circ} 18.045$. Conforme a él son relacionadas con una sociedad las siguientes personas:

a) Las entidades del grupo empresarial al que pertenece la sociedad;

b) Las personas jurídicas que tengan, respecto de la sociedad, la calidad de matriz, coligante, filial o coligada, en conformidad a las definiciones contenidas en la ley $\mathrm{N}^{\circ} 18.046$;

c) Quienes sean directores, gerentes, administradores, ejecutivos principales o liquidadores de la sociedad, y sus cónyuges o sus parientes hasta el 
das si pertenecen al mismo grupo empresarial; si una de ellas tiene la calidad de matriz, coligante, filial o coligada de la otra ${ }^{10} ; \mathrm{y}$, en general, cuando una de ellas es controlada por la otra mediante la propiedad o algún acuerdo de actuación conjunta. De acuerdo a esa definición - mutatis mutandis - son relacionadas con la universidad las empresas que, junto con ella, están bajo el control del mismo grupo o aquellas

segundo grado de consanguinidad, así como toda entidad controlada, directamente o a través de otras personas, por cualquiera de ellos, y

d) Toda persona que, por sí sola o con otras con que tenga acuerdo de actuación conjunta, pueda designar al menos un miembro de la administración de la sociedad o controle un $10 \%$ o más del capital o del capital con derecho a voto si se tratare de una sociedad por acciones.

La Superintendencia podrá establecer mediante norma de carácter general, que es relacionada a una sociedad toda persona natural o jurídica que por relaciones patrimoniales, de administración, de parentesco, de responsabilidad o de subordinación, haga presumir que:

1. Por sí sola, o con otras con quienes tenga acuerdo de actuación conjunta, tiene poder de voto suficiente para influir en la gestión de la sociedad;

2. Sus negocios con la sociedad originan conflictos de interés;

3. Su gestión es influenciada por la sociedad, si se trata de una persona jurídica, o

4. Si por su cargo o posición está en situación de disponer de información de la sociedad y de sus negocios, que no haya sido divulgada públicamente al mercado, y que sea capaz de influir en la cotización de los valores de la sociedad.

No se considerará relacionada a la sociedad una persona por el solo hecho de participar hasta en un 5\% del capital o 5\% del capital con derecho a voto si se tratare de una sociedad por acciones, o si sólo es empleado no directivo de esa sociedad.

10 Artículo 86. Es sociedad filial de una sociedad anónima, que se denomina matriz, aquella en la que ésta controla directamente o a través de otra persona natural o jurídica más del $50 \%$ de su capital con derecho a voto o del capital, si no se tratare de una sociedad por acciones o pueda elegir o designar o hacer elegir o designar a la mayoría de sus directores o administradores.

La sociedad en comandita será también filial de una anónima, cuando ésta tenga el poder para dirigir u orientar la administración del gestor.

Artículo 87. Es sociedad coligada con una sociedad anónima aquella en la que ésta, que se denomina coligante, sin controlarla, posee directamente o a través de otra persona natural o jurídica el $10 \%$ o más de su capital con derecho a voto o del capital, si no se tratare de una sociedad por acciones, o pueda elegir o designar o hacer elegir o designar por lo menos un miembro del directorio o de la administración de la misma.

La sociedad en comandita será también coligada de una anónima, cuando ésta pueda participar en la designación del gestor o en la orientación de la gestión de la empresa que éste ejerza. 
que controlen la universidad o estén bajo el control de esta última. Así, si una universidad y la empresa $X$ están bajo el mismo control de un tercero, están relacionadas entre sí. Lo mismo ocurre si la empresa $\mathrm{X}$ está bajo el control o propiedad de la universidad o si la universidad está bajo el control de la empresa X. En todos esos casos se trata de sociedades relacionadas.

En conformidad a lo anterior, parece útil distinguir tres situaciones básicas: i) la universidad y la empresa están bajo el control de un tercero o al amparo de un mismo grupo empresarial; ii) la universidad está bajo el control de una empresa; iii) la empresa está bajo el control de la universidad.

De esos tres casos básicos los más riesgosos desde el punto de vista legal son los dos primeros. En ellos la universidad puede ser empleada como fuente de excedentes para un tercero que le es ajeno. El caso iii) en cambio no parece problemático en la medida que la empresa aparece como un instrumento de la universidad y no al revés.

Así, si la universidad $\mathrm{X}$ está bajo el control de un conjunto de personas que son, por su parte, dueños de la inmobiliaria Y, la universidad puede transferir recursos a la inmobiliaria a cambio del empleo de inmuebles. Hasta ahí nada parece reprochable. Sin embargo, y como se trata del mismo controlador, nada impide que la universidad transfiera más recursos por el inmueble que aquellos que hubiera debido dar si lo hiciera por un estricto mecanismo de mercado. Ello podría ocurrir tanto en el caso i) como en el caso ii).

La legislación hasta ahora no lo impide.

Mientras ese tipo de operaciones se encuentran minuciosamente reguladas tratándose de sociedades anónimas, ello no ocurre cuando se realizan entre una sociedad anónima y una universidad que pertenecen al mismo grupo empresarial. En otras palabras, la ley es más rigurosa a la hora de controlar a una sociedad anónima que a la hora de cuidar que las universidades cumplan el fin que les es propio.

En el caso de las sociedades anónimas, este tipo de operaciones no están prohibidas; pero sí se encuentran sometidas a severos requisitos procedimentales descritos en el artículo 147 de la ley respectiva $^{11}$.

${ }^{11}$ Artículo 147. Una sociedad anónima abierta sólo podrá celebrar operaciones con partes relacionadas cuando tengan por objeto contribuir al interés 
social, se ajusten en precio, términos y condiciones a aquellas que prevalezcan en el mercado al tiempo de su aprobación, y cumplan con los requisitos y procedimientos que se señalan a continuación:

1) Los directores, gerentes, administradores, ejecutivos principales o liquidadores que tengan interés o participen en negociaciones conducentes a la realización de una operación con partes relacionadas de la sociedad anónima, deberán informar inmediatamente de ello al directorio o a quien éste designe. Quienes incumplan esta obligación serán solidariamente responsables de los perjuicios que la operación ocasionare a la sociedad y sus accionistas.

2) Antes que la sociedad otorgue su consentimiento a una operación con parte relacionada, ésta deberá ser aprobada por la mayoría absoluta de los miembros del directorio, con exclusión de los directores o liquidadores involucrados, quienes no obstante deberán hacer público su parecer respecto de la operación si son requeridos por el directorio, debiendo dejarse constancia en el acta de su opinión. Asimismo, deberá dejarse constancia de los fundamentos de la decisión y las razones por las cuales se excluyeron a tales directores.

3) Los acuerdos adoptados por el directorio para aprobar una operación con una parte relacionada serán dados a conocer en la próxima junta de accionistas, debiendo hacerse mención de los directores que la aprobaron. De esta materia se hará indicación expresa en la citación a la correspondiente junta de accionistas.

4) En caso que la mayoría absoluta de los miembros del directorio deba abstenerse en la votación destinada a resolver la operación, ésta sólo podrá llevarse a cabo si es aprobada por la unanimidad de los miembros del directorio no involucrados o, en su defecto, si es aprobada en junta extraordinaria de accionistas con el acuerdo de dos tercios de las acciones emitidas con derecho a voto.

5) Si se convocase a junta extraordinaria de accionistas para aprobar la operación, el directorio designará al menos un evaluador independiente para informar a los accionistas respecto de las condiciones de la operación, sus efectos y su potencial impacto para la sociedad. En su informe, los evaluadores independientes deberán también pronunciarse acerca de los puntos que el comité de directores, en su caso, haya solicitado expresamente que sean evaluados. El comité de directores de la sociedad o, si la sociedad no contare con éste, los directores no involucrados, podrán designar un evaluador independiente adicional, en caso que no estuvieren de acuerdo con la selección efectuada por el directorio.

Los informes de los evaluadores independientes serán puestos por el directorio a disposición de los accionistas al día hábil siguiente de recibidos por la sociedad, en las oficinas sociales y en el sitio en Internet de la sociedad, de contar la sociedad con tales medios, por un plazo mínimo de 15 días hábiles contado desde la fecha en que se recibió el último de esos informes, debiendo comunicar la sociedad tal situación a los accionistas mediante hecho esencial.

Los directores deberán pronunciarse respecto de la conveniencia de la operación para el interés social, dentro de los 5 días hábiles siguientes desde la fecha en que se recibió el último de los informes de los evaluadores.

6) Cuando los directores de la sociedad deban pronunciarse respecto de operaciones de este Título, deberán explicitar la relación que tuvieran con la contraparte de la operación o el interés que en ella tengan. Deberán también 
Pues bien. Lo que cabe ahora preguntarse es si acaso esta conocida forma de eludir la ley —o de defraudarla según el enunciado del Digesto: comete fraude a la ley quien respeta la letra pero traiciona el espíritu- puede evitarse extendiendo la regla del artículo 147 de la ley de sociedades anónimas a las universidades o si, en cambio, habrá que establecer alguna regla todavía más rigurosa.

Suele argüirse que es mejor simplemente aplicar la regla del artículo 147, o algo similar, a este tipo de operaciones. Una regla como

hacerse cargo de la conveniencia de la operación para el interés social, de los reparos u objeciones que hubiese expresado el comité de directores, en su caso, así como de las conclusiones de los informes de los evaluadores o peritos. Estas opiniones de los directores deberán ser puestas a disposición de los accionistas al día siguiente de recibidos por la sociedad, en las oficinas sociales así como en el sitio en Internet de las sociedades que cuenten con tales medios, y dicha situación deberá ser informada por la sociedad mediante hecho esencial.

7) Sin perjuicio de las sanciones que correspondan, la infracción a este artículo no afectará la validez de la operación, pero otorgará a la sociedad o a los accionistas el derecho de demandar, de la persona relacionada infractora, el reembolso en beneficio de la sociedad de una suma equivalente a los beneficios que la operación hubiera reportado a la contraparte relacionada, además de la indemnización de los daños correspondientes. En este caso, corresponderá a la parte demandada probar que la operación se ajustó a lo señalado en este artículo.

No obstante lo dispuesto en los números anteriores, las siguientes operaciones con partes relacionadas podrán ejecutarse sin los requisitos y procedimientos establecidos en los números anteriores, previa autorización del directorio:

a) Aquellas operaciones que no sean de monto relevante. Para estos efectos, se entiende que es de monto relevante todo acto o contrato que supere el $1 \%$ del patrimonio social, siempre que dicho acto o contrato exceda el equivalente a 2.000 unidades de fomento y, en todo caso, cuando sea superior a 20.000 unidades de fomento. Se presume que constituyen una sola operación todas aquellas que se perfeccionen en un período de 12 meses consecutivos por medio de uno o más actos similares o complementarios, en los que exista identidad de partes, incluidas las personas relacionadas, u objeto.

b) Aquellas operaciones que, conforme a políticas generales de habitualidad, determinadas por el directorio de la sociedad, sean ordinarias en consideración al giro social. En este último caso, el acuerdo que establezca dichas políticas o su modificación será informado como hecho esencial puesto a disposición de los accionistas en las oficinas sociales y en el sitio en Internet de las sociedades que cuenten con tales medios, sin perjuicio de informar las operaciones como hecho esencial cuando corresponda.

c) Aquellas operaciones entre personas jurídicas en las cuales la sociedad posea, directa o indirectamente, al menos un $95 \%$ de la propiedad de la contraparte. 
esa, se dice, no lesionaría la economía política del sistema y evitaría las transferencias forzosas de las inmobiliarias a las universidades.

Mi opinión, sin embargo, es que resulta mejor prohibir del todo los contratos entre una universidad y alguna sociedad relacionada, es decir, una sociedad que comparte el mismo control con la universidad. Así, entonces, si una universidad se relaciona con una inmobiliaria a la que arrienda los inmuebles que ocupa, y ambas se encuentran bajo el mismo control, la condición para que esos contratos pudieran mantenerse, si una regla de prohibición se aprobara, es que los controladores elijan de qué lado del mesón preferirían estar.

Una regla como esa, me parece a mí, evita la transferencia forzosa de bienes (la transferencia forzosa tiene el problema de que es muy difícil fijar el precio ${ }^{12}$ y su constitucionalidad es dudosa). La regla de prohibición obligaría simplemente a los controladores a escoger entre mantener el control de la universidad desprendiéndose de la sociedad de que se trata o, en cambio, optar por el control de la sociedad desprendiéndose del control de la universidad. Al revés de lo que pudiera creerse, cuando se prohíben este tipo de contratos no se desalientan los intercambios, sino los conflictos de interés con los que se realizan.

En fin, todavía existe una ventaja adicional. Una regla como la que sugiero - que no lesiona, como acabo de decir, la economía política del sistema - todavía permite separar a las instituciones de transmisión cultural, como son las universidades, de los negocios puramente mercantiles. En Chile se han hecho esfuerzos por separar a la política de los negocios ¿por qué no hacer esfuerzos similares para separar los negocios de la tarea de la transmisión de la cultura?

ii) Pero la celebración de contratos con sociedades relacionadas no es la única forma en que se infringe la regla que estamos analizando. Todavía se la infringe, y es frecuente que así ocurra, cuando los miembros de la universidad transfieren a título oneroso a un tercero el control que poseen sobre la institución.

¿Cómo podría ocurrir lo que acabo recién de señalar?, ¿cómo es posible que siendo las universidades entidades no lucrativas, respecto de las cuales no existe propiedad alguna, se transfiera sin embargo su control a cambio, todavía, de un precio?

${ }^{12}$ Uno de los contratantes puede estar en condiciones de extraer todo el excedente al otro. 
Para comprender lo anterior, es imprescindible repasar, siquiera brevemente, la manera en que una universidad puede organizarse.

Las universidades se organizan o como fundaciones o como corporaciones. El elemento que constituye esencialmente a las primeras, a las fundaciones, es el patrimonio que el fundador destina al fin que quiere servir. El elemento que constituye, por su parte, de manera esencial a las corporaciones, es el conjunto de los socios que se coalicionan para perseguir un fin de interés público. Ahora bien, la ley no establece qué carácter han de poseer los socios: para que una corporación exista basta que los haya.

Y ahí entonces surge el problema.

Porque ocurre que algunas universidades se organizan como corporaciones sin fines de lucro; pero sus socios son personas jurídicas lucrativas. Así, la universidad X es incuestionablemente sin fines de lucro, puesto que es una corporación; pero los miembros que integran a esta última, aquellos cuya voluntad la gobierna, pueden ser, en el derecho vigente en Chile, personas jurídicas con fines de lucro, por ejemplo, sociedades comerciales o civiles. Así entonces el control de la universidad puede ser objeto de una transferencia onerosa. Ello ocurre si se vende la participación en la sociedad que, por integrar la corporación, contribuye a forjar su voluntad. Se explica así entonces el misterio, tantas veces repetido entre nosotros, que una universidad mantenga incólume su carácter sin fines de lucro; pero sea, al mismo tiempo, y a la vista y paciencia de todos, objeto de transacciones comerciales.

Seguramente todos ustedes recuerdan el Caso Chispas. En este caso un grupo de managers transformó las indemnizaciones a que tenían derecho en acciones de la compañía que administraban. Sus acciones tenían, sin embargo, una particularidad: los derechos económicos sobre el capital estaban por debajo de los derechos políticos que los tenedores de esas acciones tenían a la hora de elegir al directorio. Los tenedores de esas acciones decidieron venderlas a un precio superior atendido el hecho que no vendían sólo el capital, sino el control político sobre él. La operación fue considerada un escándalo y quienes participaron de ella sufrieron altísimas penas pecuniarias. ¿Cuál era el pecado de esos managers? Su pecado fue haber vendido a precio preferente el control o los derechos políticos de una sociedad anónima en perjuicio de los minoritarios.

Pues bien. Si los managers de que se trata hubieran vendido el control de una universidad — es decir, si hubieran vendido las acciones 
de una compañía que integra la asamblea de socios de una corporación universitaria y hubieran cobrado un sobreprecio de control- nadie podría haberles dicho nada. La operación, bajo el derecho vigente, habría sido perfectamente lícita.

¿Es correcto - ya no bajo las reglas del derecho vigente, sino ahora desde el punto de vista de un buen diseño universitario- que pueda transferirse el control de las universidades a título oneroso?

Mi opinión es que no, creo que eso no es correcto.

Las universidades deben ser entidades autónomas, provistas de una voluntad propia, y no organizaciones dependientes de un poder extraño o ajeno a sí misma. Menos organizaciones cuya estructura de poder dependa de las leyes bajo las cuales circulan las mercancías. ¿Cómo va a ser sensato que una universidad no sepa cuál es la voluntad que la gobierna porque esa voluntad puede cambiar, de un día para otro, al compás de la oferta y la demanda?

Para evitar lo anterior, es necesario establecer que los miembros de la corporación universitaria deban ser, en cualquier caso, personas naturales. De esa manera se evita que los miembros de la corporación sean sociedades comerciales y que (como ocurre hoy) la venta de las acciones o de la cuota de participación en estas últimas equivalga a la venta del control de la universidad. Igualmente deben preverse reglas que eviten la cesión a cualquier título del control o gobierno de la universidad $^{13}$.

iii) La consideración anterior - relativa a dónde radica el poder que gobierna a la universidad, si en el intercambio o en la deliberación - obliga a considerar, siquiera brevemente, el tema del gobierno de las universidades. Creo, como insistiré de inmediato, que el gobierno de las universidades se relaciona directamente con el tema del lucro que venimos considerando (una revisión de las relaciones entre formas de gobierno y respeto de las reglas, en David Farber, "Restoring Trust after Fraud: Does Corporate Governance Matter?”, pp. 539-561). En el

${ }^{13}$ Las reglas debieran ser similares a las que siguen:

- Se prohíbe cualquier acto o contrato por el que el directorio ceda o transfiera, total o parcialmente, y a cualquier título, sus funciones esenciales o se comprometa a ejercerlas bajo una determinada modalidad.

- Hay objeto ilícito en todo acto o contrato por el que se transfiera, a título gratuito u oneroso, una posición de control en una corporación o fundación universitaria, aunque ello se haga modificando los estatutos. 
mismo punto - la relación entre gobierno universitario y reglas - en Secretary of Education and Training, Review of University Governance (Australia, 2002).

Como todo el mundo sabe (Coase, si no recuerdo mal, fue uno de los primeros que llamó la atención acerca de esto en "The Nature of the Firm", pp. 386-405) las empresas que funcionan en el mercado se organizan, paradójicamente, en términos de no mercado, como un conjunto de recursos gobernados por un poder central. Todo esto plantea el problema, suficientemente conocido, del gobierno de las organizaciones: quién manda a quién y cómo se controla a los que mandan.

En el caso de las sociedades anónimas abiertas, este problema se resuelve más o menos de la siguiente forma: el poder final se radica en los propietarios reunidos en la junta de accionistas quienes, por su parte, y en proporción a la propiedad, designan a un directorio el que, a su turno, designa a los administradores directos. La tarea del directorio, sin embargo, no es cuidar los intereses de quienes los designaron sino los intereses de la sociedad o de la empresa en su conjunto. El principal es la sociedad (cuya voluntad se actualiza en la junta de accionistas) y el agente es el directorio (cuyo papel es fiduciario y consiste en cuidar que la administración no traicione los intereses del principal). Ahora bien, a fin de asegurar que los directores cumplan las reglas de la sociedad y cuiden los intereses sociales (es decir, los intereses de todos y no sólo de los minoritarios) la ley dispone que los directores son personalmente responsables por los acuerdos a los que concurren: responden, pues, con su patrimonio personal si abandonan el estándar de cuidado que la ley impone para los intereses sociales.

En suma, el problema del gobierno de las sociedades anónimas se resuelve de manera correcta en la medida que la relación de agencia es clara (se sabe quién es el principal y quién el agente) y la responsabilidad se encuentra bien definida (recae, como acabamos de ver, personalmente sobre los directores).

¿Qué ocurre, sin embargo, en las universidades, especialmente en las universidades privadas creadas luego de 1981 ?

Lo que ocurre es que en esas universidades ni la relación de agencia es clara, ni la responsabilidad se encuentra bien definida.

Desde el punto de vista legal, las corporaciones y fundaciones se constituyen con fines de interés público o social, en cualquier caso, con 
fines de servicio distintos de la mera suma de los intereses de quienes las constituyen. Ésta es una conclusión que en la literatura ya no se discute. Por lo mismo, las corporaciones y fundaciones - que es, como sabemos, la forma en que se constituyen las universidades - deben servir los intereses y los propósitos para los que fueron creadas y la labor de todos sus órganos es asegurar que ello ocurra. La relación de agencia en las universidades, en consecuencia, debe establecerse entre los propósitos de la universidad y el directorio.

Desgraciadamente ello no suele ocurrir en la práctica. En la práctica, que es donde importa, los controladores de las universidades suelen actuar como propietarios de ellas y el directorio, que a veces coincide con esa relación de propiedad, actúa como su agente. En otras palabras, en las universidades privadas se arriesga el peligro de reproducir la relación de agencia de las sociedades, cuando se trata de realidades que, sin embargo, son muy distintas. La ley, por su parte, nada dice respecto de los deberes del directorio de una universidad. Esos deberes, hemos visto, no pueden ser otros que los de cautelar el interés que la corporación o la fundación universitaria declaró servir al momento de constituirse y no los intereses de los controladores. Sin embargo, a diferencia de lo que ocurre en las sociedades anónimas, el derecho vigente en Chile guarda silencio acerca de los deberes de los directores de universidades (por supuesto, alguna regla puede derivarse del mandato; pero no existe, como digo, regla explícita alguna en esta materia lo que crea incertidumbre y favorece la anomia).

A lo anterior se suma que tampoco existe una regla de responsabilidad personal de los directores de universidades por los acuerdos a que concurran y que acaben perjudicando el interés de la corporación o de la fundación.

Este problema es especialmente severo.

Ninguna regla tendrá éxito en estas materias si no se exige que exista un directorio explícita y personalmente responsable de hacerla cumplir. Como todos saben, es más eficiente socialmente poner el riesgo de cargo de aquellos que pueden evitarlo al menor costo. Siguiendo ese principio, parece obvio que es necesario, y eficiente, poner el riesgo de incumplimiento de la ley por parte de las universidades de cargo de los directores, instituyendo a la Superintendencia con la titularidad de la 
acción para ejercerla, de oficio o a petición de parte. No es difícil, desde el punto de vista técnico, prever esas reglas ${ }^{14}$.

Así entonces, para hacer cumplir la regla que prescribe que las universidades han de ser sin fines de lucro, es necesario prohibir los contratos con sociedades relacionadas, impedir que las corporaciones se organicen con miembros que equivalgan a sociedades comerciales o civiles y disponer la existencia de directorios independientes y personalmente responsables cuyo deber sea servir los fines para los que la universidad fue autorizada.

¿Acabarán las prácticas que hemos relatado una vez qué reglas como las que menciono se adopten?

Es probable que no. Es más fácil, dijo Zizek, imaginar el fin del mundo que la muerte del capitalismo y de su casi infinita plasticidad ${ }^{15}$;

${ }^{14}$ Para ello habría que establecer reglas como las que siguen.

- Las universidades debieran administrarse por un directorio o consejo directivo designado en la forma prevista por los estatutos de la respectiva corporación o fundación. La designación debe ser por el plazo que señalen los estatutos, el que no debiera ser inferior a tres años.

- Una vez nombrados, los directores son independientes de todo interés particular y no podrán ser removidos de su cargo sino por mayoría del directorio y por causa grave señalada previamente en los estatutos.

- Será deber esencial de los directores velar por el fiel cumplimiento de los estatutos de la Corporación o Fundación y el íntegro respeto de la ley. En el ejercicio de sus funciones, los directores universitarios no representan el interés de quien los designó ni cualquier otro interés particular, sino que actúan en interés del conjunto de la Corporación o Fundación.

- Los directores deberán emplear en el ejercicio de sus funciones el cuidado y diligencia que los hombres emplean ordinariamente en sus propios negocios y responderán solidariamente, y con su patrimonio, de los perjuicios causados a la Corporación o Fundación. Corresponderá a la Superintendencia de oficio o a petición de parte, perseguir judicialmente esa responsabilidad.

- Si la universidad recibe financiamiento público, al menos uno de sus directores deberá ser designado por el Estado. La tarea de este director será la de tutelar el interés público comprometido en la administración de la universidad.

- Es nula toda estipulación del estatuto que tienda a liberar o a limitar la responsabilidad de los directores a que se refiere el inciso anterior.

- Es función esencial del directorio de la Corporación o Fundación universitaria la de supervigilar la administración financiera y patrimonial de la entidad cuidando que se ciña estrictamente a la ley.

Las universidades actualmente existentes tendrán un plazo de seis meses para adecuar sus órganos de gobierno a lo previsto en las reglas anteriores.

15 http://philosomatic.tumblr.com/post/11602788564/slavoj-zizekspeaks-to-occupy-wall-street. 
pero así y todo no cabe duda que con reglas como esas el sistema funcionará mejor y estará, más que hoy día, a la altura de sus compromisos públicos.

\section{REFERENCIAS BIBLIOGRÁFICAS}

Consejo de Defensa Fiscal. "Informe". En RDJ, tomo XXXIX. Santiago de Chile.

Derrida, J. Universidad sin Condición. Madrid: Trotta, 2002.

Farber, David. "Restoring Trust after Fraud: Does Corporate Governance Matter?" The Accounting Review, Vol. 80, № 2.

Fichte, J.G., F. Schleiermacher, W. von Humboldt, F. Nietzsche, De Lagarde, M. Weber, M. Scheler, K. Jaspers. La Idea de la Universidad en Alemania. Buenos Aires: Sudamericana, 1959.

Secretary of Education and Training. Review of University Governance. Australia, 2002.

Zizek, Slavoj. En http.//philosomatic.tumbir.com/post/11602788654/slavojzizek-speaks-to-occupy-wall-steet. 